\title{
Promotion of local government open data for sightseeing events
}

\author{
Mayu Urata (Graduate School of International Development, Nagoya University, mayu@nagoya-u.jp) \\ Kazuma Ogishima (Graduate School of Information Science, Nagoya University, ogishi4529@nagoya-u.jp) \\ Mana Fukuyasu (Graduate School of Information Science, Nagoya University, fukuyasu@nagoya-u.jp) \\ Mamoru Endo (Graduate School of Information Science, Nagoya University, endo@is.nagoya-u.ac.jp) \\ Takami Yasuda (Graduate School of Information Science, Nagoya University, yasuda@is.nagoya-u.ac.jp)
}

\begin{abstract}
In anticipation of the Tokyo Olympics, Japan is attaching importance to create an attractive sightseeing region. As one method to activate sightseeing by utilizing local regional resources, open data promotion is currently paid attention. However, there are many local governments that have not started to open data promotion because they are concerned that their work load will be increased and they have no idea about its needs since there are still few utilization cases of open data. The purpose of this study is to open data promotion at autonomous works, and an open data promotion of sightseeing event information by co-operating with local government was conducted. Regarding open data promotion that was conducted, this study worked on converting information that local government has kept so far, to open data, developing event guide application by utilizing it, and revealing its usefulness by a demonstration experiment.
\end{abstract}

\section{Keywords}

sightseeing event, open data, application, local government, cooperation between public and private

\section{Introduction}

The movement of open data promotion in Japan has also spread in the sightseeing industry. Because of open data utilization by MICE promotion to create a tourism-oriented country [Hashimoto and Imagawa, 2014] and public cloud system work by Ministry of Internal Affairs and Communications, local government's open data promotion of sightseeing information has grown more and more.

In addition, in "Open data 2.0" advocated in 2016, it is required to deepen by not only working on mainly data publication as usual, but also solving social problems and political problems. The Tokyo Olympics is set as one of the areas to be improved, and problems directly related to sightseeing have been suggested, such as a promotion for foreign travellers visiting Japan and an appeal of the attractiveness of Japanese culture. Open data promotion is attaching more importance on the sightseeing industry.

Research regarding open data promotion on sightseeing information from 2014 was worked on, and it was attempted to make sightseeing event information as open data, and develop the contents by utilizing it [Ogishima et al., 2015]. However, it was tried to create open data in assumption of application development, without consideration of the situation and the workloads of local governments that are actually in charge of this role. To make open data promotion be accepted by more local governments, it is needed to conduct open data promotion with understanding and approval of local governments.

Therefore, the purpose of this study is open data promotion with considering the local government's acceptability. The local government's acceptability means new ideas, techniques that are accepted by the local governments and the officers with acquiring their understanding and acceptance. Based on trial and practice of creating open data conducted in 2014, open data of sightseeing event information by local government was promoted and event guide application by utilizing published open data was developed. Then, the usefulness and problems of converting event information to open data, from the demonstration experiment result by using this application, are considered.

\section{Trial and problems of creating open data}

2.1 Trial of creating open data and application development

In 2014, it was tried to convert sightseeing event information, which local government promoted, to open data at a regional sightseeing event held in Higashi-ku, Nagoya, and developed application by utilizing this open data. It was tried to create open data with using open data platform "LinkData" (http://linkdata. org). Information for open data was sorted, based on leaflet distributed in the event, and information from event's formal website was also examined. By utilizing this trial open data and bus information open data published by transportation authority of Nagoya, a sightseeing event guide application was developed.

A demonstration experiment to evaluate the usefulness of application utilizing trial open data was conducted, and received a high reputation. It means the information published by open data as trial is useful information for the event's participants. This activity was highly evaluated by Nagoya and the event practice committee, and it was decided the event information in 2015 was published as formal open data of Nagoya. However, it revealed that there were actually various problems to promote local government open data.

\subsection{Problems of local government open data promotion}

(1) Increase of workloads

According to Hayashida, the number of workers and cost of 
local government is decreasing [Hayashida, 2007]. On the other hand, the workload per local government's officer is increasing due to decentralization of authority. There are various requirements of open data by the private sector, however, local governments need to collect and sort out the information to meet these needs. Therefore, concern of the increasing workloads is necessary. It is too much work for local government's officers to take care of open data promotion in addition to numerous existing tasks.

(2) Lack of knowledge of local government's officers

Open data means public data that is available for secondary use and decipher by machine [MIC, 2014]. However, most of the officers in the concerned department who keep original data of open data do not have any knowledge about information processing and sometimes cannot process original data as open data appropriately.

(3) Only a few cases to utilize open data

Creation of public service is expected as a result of open data promotion. However, almost no utilization cases have been reported in many local governments [LASDEC, 2014]. Therefore, local governments cannot acquire sufficient effect from open data promotion, and there are many regions that cannot process open data promotion smoothly [Ogishima et al., 2015].

\subsection{Policy of this research}

Based on the problems stated above, the purpose of this research is open data promotion considering acceptability by local governments. With considering the following three points as necessary elements, the methods to promote open data in current autonomous works were chosen.

(1) Creating open data of existing information

Aoki insists it is effective to work on open data promotion by starting from information that has been published [Aoki, 2013]. Also, Shimizu insists that perfection level is enhanced by development based on data rather than needs [Shimizu, 2013]. Therefore, it is better to create open data from the information that has been published by the local government, if acceptability is considered.

(2) Cooperation with knowledgeable persons

Koike and associates insist on the necessity of cooperation of public and private regarding local government's open data, with showing the example of open data promotion in Suzaka-shi, Nagano [Koike et al., 2014]. Also, Hattori and associates tried open data promotion associated with industry-government-academic-private by SNS, and described that the local government requested a knowledgeable person's support [Hattori et al., 2015]. As one of the contents, promotion of cooperation of public and private is suggested in open data promotion. To support local government's lack of knowledge about open data, it is better to ask for a knowledgeable person's support and proceed with cooperation.
(3) Suggestion of utilization cases

Local governments regard creation of utilization cases as an effective method for open data promotion. By suggesting utilization cases, the advantage of open data creation becomes embodied and it is easier to receive understanding and agreement from the concerned department about keeping data. Furthermore, it makes it easier to understand which kind of needs for data publication actually exist.

\subsection{Regarding the research target}

In this research, a regional sightseeing event "Arukou! Bunka no Michi! (Let's Walk the Cultural Path)" is the target event as the same in 2014, and event information is converted to open data. The event is held on 3rd November every year, and it was the 16th one in 2015. It is located in the "Cultural Path" area where moderate heritages of Nagoya are preserved, and precious historical heritage is promoted on the event day. The leaflets are distributed to event participants so that they can check the events held in each of sites in the area, and they can enjoy events based on the information on leaflet (Figure 1).

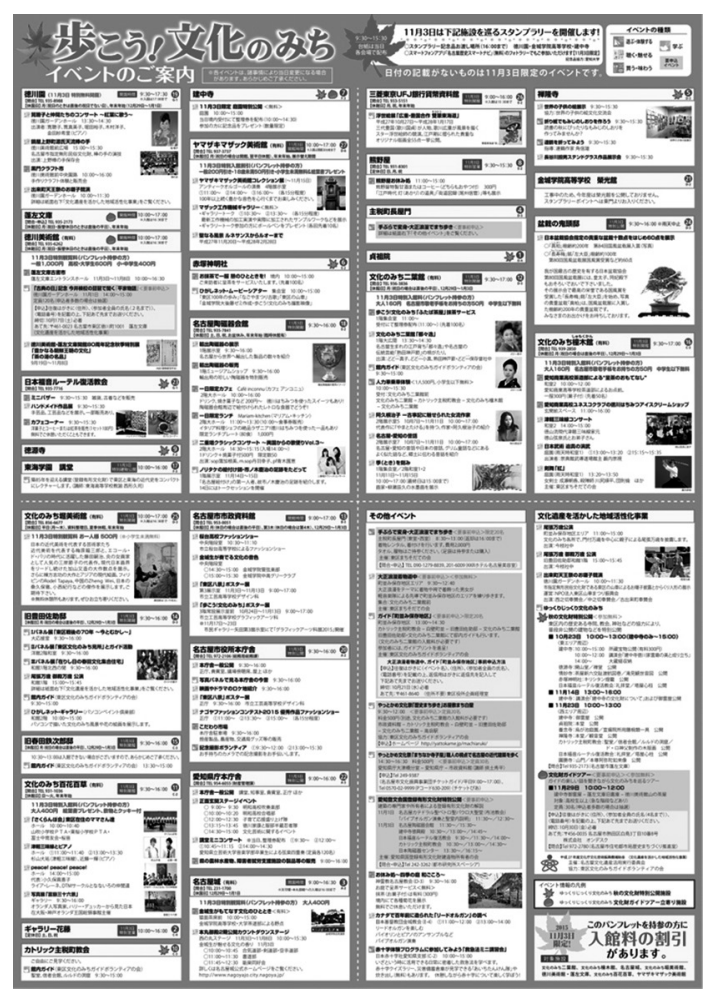

Figure 1: "Arukou! Bunka no Michi!” leaflet

\section{Open data creation of sightseeing event information \\ 3.1 Information converted to open data}

Information for converting to open data is the event information published on the leaflet (Table 1). The information on the leaflet has been collected from the event owner by Higashi$\mathrm{ku}$ and managed on Excel file after arranging it every year. Based on this Excel data, the leaflet is created and published. Therefore, to enhance human readability, multi-information 
Table 1: Information converted to open data

\begin{tabular}{|c|c|c|c|c|c|c|c|c|c|}
\hline $\begin{array}{c}\text { Stamp } \\
\text { rally } \\
\text { serial No. }\end{array}$ & Event location & Regular holiday & Tel. No & Fee & $\begin{array}{l}\text { Facility open- } \\
\text { ing hours on } \\
\text { 3rd November }\end{array}$ & Event hours & Site & Plan & Genre \\
\hline 19 & Tokugawa-en & $\begin{array}{l}\text { Mon (If Monday } \\
\text { is holiday, first } \\
\text { week day after } \\
\text { Monday), New } \\
\text { year (29th Dec-1st } \\
\text { Jan) }\end{array}$ & $935-8988$ & $\begin{array}{l}\text { For free on } \\
\text { 3rd Nov as a } \\
\text { special case }\end{array}$ & $\begin{array}{l}9: 30 \text { to } 17: 30 \\
\text { Entrance is till } \\
17: 00\end{array}$ & $13: 30$ to $14: 30$ & $\begin{array}{l}\text { Tokugawa- } \\
\text { en Garden } \\
\text { hall }\end{array}$ & $\begin{array}{l}\text { Concert of Satoko } \\
\text { Kakei and friend } \\
\text { - Song for autumn } \\
\text { color - Performer: } \\
\text { Satoko Kakei, Ma- } \\
\text { miko Kakei, Yuko } \\
\text { Hotta, Yoko Kimura, } \\
\text { Sagiri Kaneta (Piano) }\end{array}$ & Listen $\bullet$ Attract \\
\hline 18 & $\begin{array}{l}\text { Nagoya } \\
\text { pottery } \\
\text { hall }\end{array}$ & $\begin{array}{l}\text { Sat, Sun, Holiday, } \\
\text { Obon holiday, } \\
\text { New year (Tempo- } \\
\text { rary holiday can } \\
\text { be occurred.) }\end{array}$ & $935-7841$ & & $\begin{array}{l}\text { Special open- } \\
\text { ing on } 3 \mathrm{rd} \mathrm{Nov} \\
9: 30 \text { to } 16: 00\end{array}$ & $9: 30$ to $16: 00$ & $\begin{array}{l}1 \mathrm{~F} \text { Exhibi- } \\
\text { tion hall }\end{array}$ & $\begin{array}{l}\text { Exhibition of export } \\
\text { pottery introduction } \\
\text { of a number of prod- } \\
\text { ucts exported to the } \\
\text { world from Nagoya. }\end{array}$ & Listen $\cdot$ Atrract \\
\hline
\end{tabular}

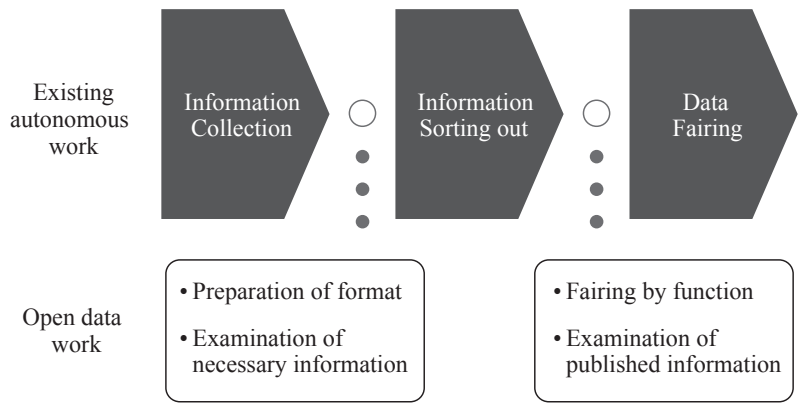

Figure 2: Open data work at existing local government

is described in one cell or multi-cells are combined intricately and so on. This means it is not suitable for machine readability. Therefore, based on existing Excel data for the event information management, an easy mathematical scheme such as conditional equation was applied, and an Excel format to make format with better machine readability was created. Based on this format, Higashi-ku sorted out collected information as usual, and formed data to be published as open data (Figure 2).

As contents of the information converted to open data, equivalent data as the contents was published on the leaflets. The information about events owned by community residents or private businesses is not converted to open data this time since there are possibilities that the content's may change until just before holding the event or it is too difficult to make owners understand about open data.

\subsection{Creation of open data}

Regarding the publication of formed information as open data, it was proceded to right handling of "CC-BY-SA (displayinheritance)" to data. It is because the Higashi-ku intensions which are "we would like to take care of open data very carefully since it is just first trial" and "it is more secure to keep information under Higashi-ku management" was followed. This data processed by right handling was published as open data on 1st October 2015. Open data was published on the page of Higashi-ku in the Nagoya website for a limited time only (Figure 3).

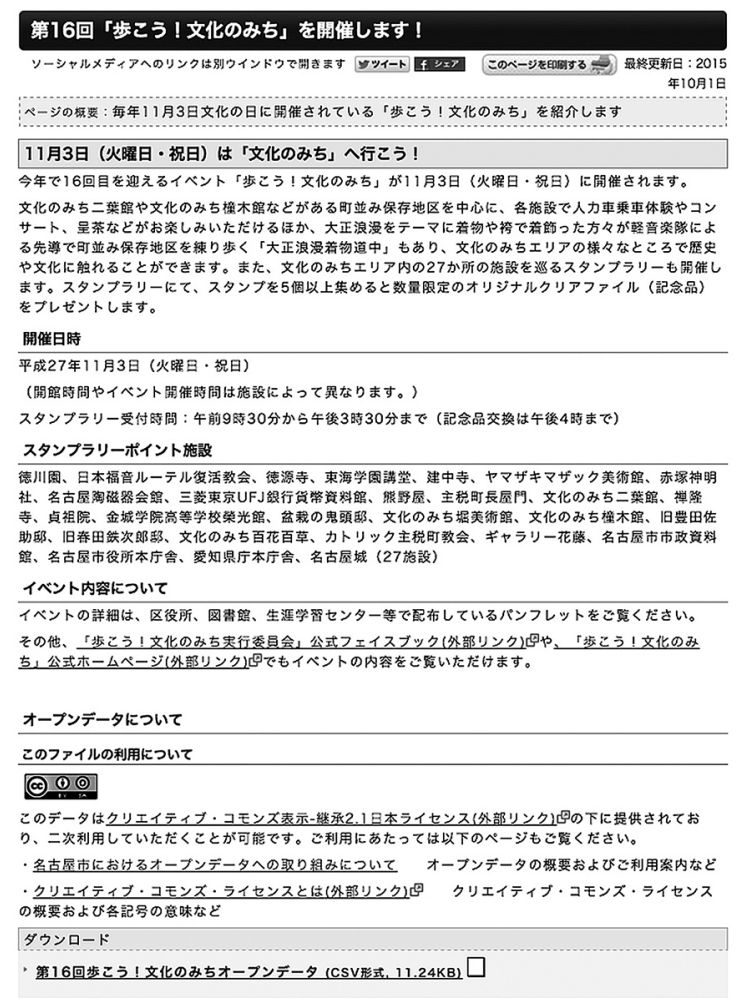

Figure 3: Page of Higashi-ku in the Nagoya website

\subsection{Application development}

By utilizing published open data, a 2015 version of the sightseeing event guide application "Arukou! Guide" was developed (Figure 4). Published open data was registered to open data platform LinkData, and an application by utilizing "LinkData App" which is the sister website "LinkData App" was developed. In LinkData App, it is possible to develop Web application in the browser by utilizing open data on LinkData. Therefore, everyone can work on the contents development in an Internet environment.

Since application function of the 2014 version was reputed well, it was decided to set up the same function (Table 2). In 2014, an open data information of trial was used, but in 2015 

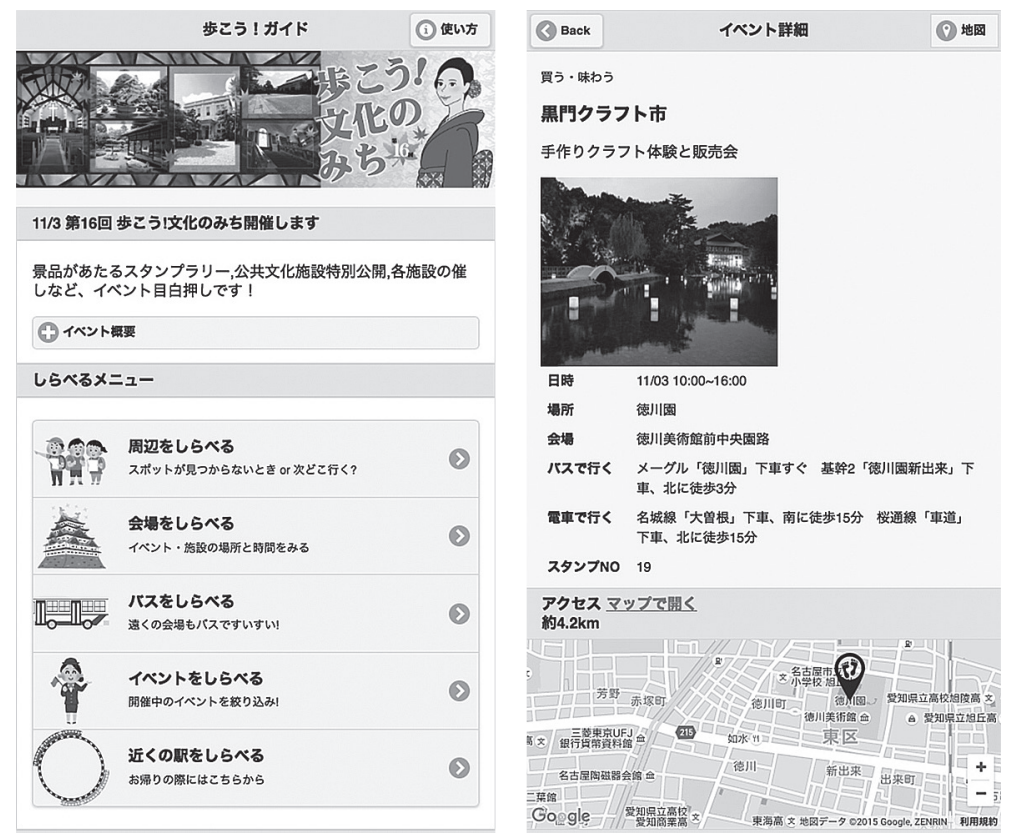

Figure 4: "Arukou! Guide” Screen display example

Table 2: Function list

\begin{tabular}{ll}
\hline \multicolumn{1}{c}{ Function } & \multicolumn{1}{c}{ Contents } \\
\hline Check surrounding & $\begin{array}{l}\text { List of event spaces around current loca- } \\
\text { tion \& bus stops and route navigation }\end{array}$ \\
\hline Check event space & List of event spaces and route navigation \\
\hline Check bus & List of event spaces in each of bus line \\
\hline Check events & $\begin{array}{l}\text { List of event held in each of event spaces } \\
\text { and search for event time }\end{array}$ \\
\hline Check station nearby & $\begin{array}{l}\text { Lists of stations in cultural road area and } \\
\text { route navigation }\end{array}$ \\
\hline
\end{tabular}

creation of open data by using published open data information by Higashi-ku was tried and made up for lack of information from the formal website.

To guide a sightseeing event, it is needed not only information about event contents held in each of spots but also information for access to sightseeing spots where these events are

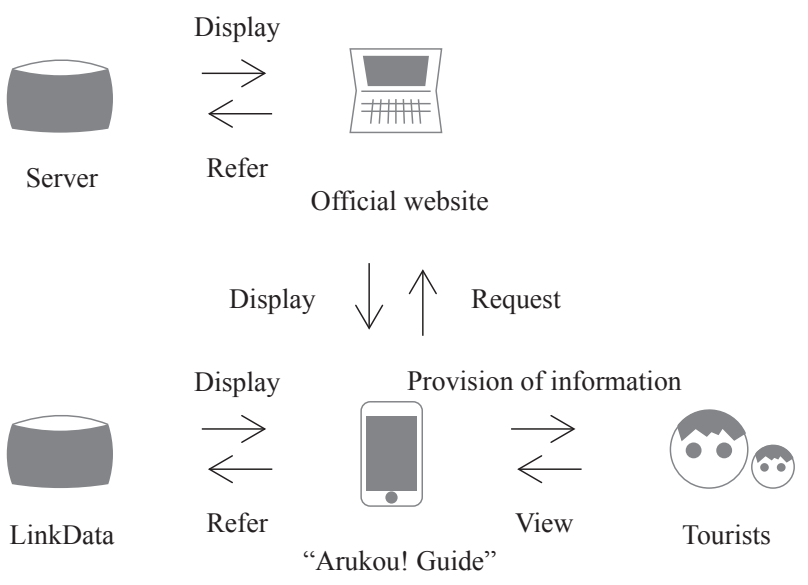

Figure 5: Association with formal website held. In the existing leaflet made of paper, access information was only displayed by a map and event information was summarized in each of spots. On the other hand, in the guide by application, regarding event information, it was possible to search an event by genre and time. Regarding access information, it was possible not only to display a map but also to list bus information and set up the route navigation function. Also, by association with the formal website, it was possible to make up for lack of detail information (Figure 5). By this guide function, visitors can choose information they need. It created an event guide more specialized to each of the visitor's needs compared to the usual one.

\section{Reputation of open data}

\subsection{Recognition experiment}

(1) Outline

In the "16th Arukou! Bunka no Michi" held in 2016, a recognition experiment to evaluate the usefulness of "Arukou! Guide" was conducted. The number of persons being tested was 21 . Their ages were 20 s and 30 s and about $80 \%$ were 20s. They gathered in "Akatsuka Shinmeisha" located in the cultural path area, and each of them was sightseeing for about 4 hours with utilizing the leaflet and application after explanation of how to use the application. Spots were randomly located in 29 places in the area, and they went around their preferred spots. After a certain time had passed, they came back to Akatsuka Shinmeisha again, and answered for each of the items on an evaluation paper.

(2) Result and consideration

Table 3 is the summary of the questionnaire results. Regarding 4 functions of the application developed by utilizing open data, the average value, from rate 5 for "I agree very much" to rate 1 is for "I totally disagree" was calculated. 
Table 3: Experiment evaluation

\begin{tabular}{llc}
\hline \multicolumn{1}{c}{ Question } & $\begin{array}{c}\text { Evaluation of } \\
\text { this year (Aver- } \\
\text { age) }\end{array}$ & $\begin{array}{c}\text { Evaluation of } \\
\text { last year (Aver- } \\
\text { age) }\end{array}$ \\
\hline Was the function to check surroundings useful? & 4.05 & 4.05 \\
\hline Was the function to check event sites usuful? & 3.81 & 3.71 \\
\hline Was the function to check buses usuful? & 3.62 & 3.86 \\
\hline Was the function to check events useful? & 3.52 & 3.85 \\
\hline
\end{tabular}

It was possible to receive a certain reputation for each of the functions. Compared to the experiment results in 2014, it was possible to receive the same level of results. Positive comments from participants such as "Good and necessary information for events is summarized." and "It is useful to search for event places close from the current location were received." On the other hand, there were also negative comments such as "The map on the leaflet is better to use." and "I need a display of the recommended course."

Event information converted to open data in this research was mainly used for the "Search event" function. The amount of open data of event information in 2015 decreased in comparison of the one in 2014, due to the local government's intension. However, it did not affect the reputation in 2015 so much. It means that open data on usual autonomous work also has sufficient utility.

Furthermore, in this research, the information of event places could not be published as open data due to the intension of the facility's management. Most of the event places are a usual sightseeing facility, and it is assumed that creation of a new service can be expected by converting the information to open data. In addition, the persons being tested suggested information of the restaurants and public toilets should be listed too. Especially there were many needs for restaurant information since recognition experiment was conducted in the daytime, and a high compatibility of sightseeing and foods could be found.

\subsection{Consideration of open data creation}

From the evaluation of a recognition experiment, useful function of application could be created by open data of a sightseeing event information. It can be said that it is possible to develop a new public service from open data of existing data and there is an expanding possibility for various services. Also, by open data promotion involving a knowledgeable person, knowledge about open data promotion is provided to local governments and it will become easier to add open data work to usual work. Therefore, it can be expected to develop open data promotion with minimizing the load of local governments.

In this research, open data promotion of sightseeing event information based on trial and practice of open data that was conducted. Based on "Arukou! Guide", it has been suggested in detail which kind of information needs to be converted to open data and then which kind of service will be created from this data. Accordingly, consideration of creation of open data based on existing utilization cases of open data and actual service, that a knowledgeable person suggests, will help open data promotion with consideration of local government's acceptability.

Local governments have conventionally organized information pertaining to operations by using Excel. As indicated in this research, converting information that has been conventionally communicated can also lead to creation of useful public services if converted to open data upon considering machine readability.

On the other hand, there are limits for local governments to organize information with machine-readable formatting. Website and open data linkage systems are currently being developed by private enterprises, including CMS (Contents Management System) that converts the entered data on websites into appropriate formatting as open data. Usage of these systems will anticipate further promotion of open data conversion for conventional information.

\section{Conclusion}

In this research, open data as a method to activate regional sightseeing was focused on and the purpose of open data promotion with consideration of local government acceptability was worked on. By cooperating with a knowledgeable person based on utilization cases, open data work was added to usual work and open data creation of published information was conducted. Also, an application utilizing actual published open data was developed and new utilization cases of open data on a sightseeing event were suggested.

The problems in the future are to consider about open data creation of necessary information such as sightseeing facilities and restaurants, to work on interoperability of service on purpose of open data creation of sightseeing event information in not only Higashi-ku but also other regions, and to expand the functions of the sightseeing event guide application.

\section{Acknowledgements}

This work was supported by JSPS KAKENHI Grant Numbers JP25280131, JP15K00448, and JP15K16097.

\section{Reference}

Aoki, K. (2013). The problem of open data by local government. Proceedings of the 2013 Annual Meeting of the Society of Socio-Informatics, 211-216. 
Hashimoto, H. and Imagawa, Y. (2014). Conversion of regional information into open data and their utilization for enhancement of international competitiveness in MICE. Fujitsu, Vol. 65, No. 6, 93-98.

Hattori, H., Kanematsu, A., Urata, M., Endo, M., Yasuda, T., Shimoyama, S., and Toyoda, T. (2015). Proposals and trials of applying social networking service to open data promotion by municipalities. Proceedings of the 5th Meeting of Chubu Branch, the Society of Socio-Informatics, SSICJ2015-1, 10-13.

Hayashida, K. (2007), For streamlining of administrative work: Detail method of local government's work innovation. NRI Public Management Review, Vol. 49, 1-5

Koike, Y., Fukuyasu, M., Urata, M., Endo, M., Naka, T., Yamada, M., Miyazaki, S., and Yasuda, T. (2014). Local informatization activities and its future prospects for open data promotion. Proceedings of the 3th Meeting of Chubu Branch, the Society of Socio-Informatics, SSICJ2014-1, 3336.

Local Authorities Systems Development Center (2014). Investigation research regarding open government in regional public institution.

Ministry of Internal Affairs and Communications (2014). Promotion of open data utilization. 2014 White Paper Information and Communications in Japan, 138-153.

Ogishima, K., Kato, F., Fukuyasu, M., Urata, M., Endo, M., and Yasuda, T. (2015). Consideration on standardizing formats for open data: Case study of utilizing tourism event information. Proceedings of the 2015 Annual Meeting of the Society of Socio-Informatics, 204-209.

Ogishima, K., Kato, F., Fukuyasu, M., Urata, M., Endo, M., and Yasuda, T. (2015). Creation of open data of sightseeing event information and practice. Proceedings of the 1st Meeting of the Society for Tourism Informatics, 5-8.

Shimizu, T. (2013). Application development with open data in Hackathon. Proceedings of the 2013 Annual Meeting of the Academic Association for Organizational Science, Vol. 2, No. 1, 38-43.

(Received November 7, 2016; accepted December 14, 2016) 